\title{
Abordagem na formação do cirurgião- dentista clínico geral para atuar no serviço público e privado. Revolução na prática de ensino
}

\author{
Ana Beatriz da Silva Freixinho*, Leila Chevitarese** \\ * Mestranda do Programa de Pós- Graduação em Odontologia da \\ Universidade do Grande Rio (UNIGRANRIO) \\ ** Mestre e Doutora em odontopediatria pela UFRJ, professora \\ do curso de graduação em odontologia da UNIGRANRIO e \\ coordenadora do Pró- Saúde I (UNIGRANRIO)
}

\section{RESUMO}

Na maioria das instituições de ensino em odontologia a tendência de formação do cirurgião- dentista ainda é predominantemente elitista e tecnicista, valorizando mais as ciências básicas do que os aspectos de promoção e prevenção à saúde, sendo voltada para a prática liberal, no entanto, os atuais Projetos Políticos Pedagógicos procuram se adequar a realidade do Sistema Único de Saúde(SUS), proporcionando uma formação profissional mais ajustada às perspectivas da atenção básica. O objetivo deste trabalho foi discutir sobre a abordagem na formação do cirurgião dentista clínico geral para atuar no serviço público e privado. A abordagem na formação do graduando em odontologia, deve ser ampla, tornando o futuro profissional apto para atuar no serviço privado e público.

\section{DESCRITORES}

Estudantes de odontologia. Educação em odontologia. Educação superior.

$\mathbf{N}$ a década de 70, o currículo mínimo do curso de odontologia foi aprovado no parecer $840 / 70 \mathrm{de}$ 11 de novembro. Neste currículo o ensino odontológico era descrito como sendo eminentemente técnico, alertando a importância da inclusão de matérias de cultura geral e ciências humanas no currículo pleno das escolas de odontologia, com o intuito de ampliar os horizontes intelectuais do profissional e integrá-lo no contexto sócio- cultural do país e do mundo. ${ }^{3}$

Em 1996, foi criada a Lei de Diretrizes e Bases/96 da Educação Nacional, a qual regulamenta a educa- ção escolar, se desenvolvendo por meio do ensino em instituições próprias. ${ }^{11}$ Esta lei culminou com as Diretrizes Curriculares dos Cursos, dentre eles o de Odontologia, em 2001.

Passados os anos, com a nova Lei de Diretrizes Curriculares Nacionais dos Cursos de Graduação de Odontologia (Parecer CNE/CES n ${ }^{\circ} 1.300 / 01$, aprovado em 06/11/2001), o perfil da formação do cirurgião-dentista se tornou generalista, humanista, crítico e reflexivo para atuar em todos os níveis de atenção à saúde, com base no rigor técnico e científico, sendo assim, o profissional é capacitado para exercer atividades referentes à saúde bucal da população, pautado em princípios éticos, legais e na compreensão da realidade social, cultural e econômica do seu meio, dirigindo sua atuação para a transformação da realidade em benefício da sociedade. ${ }^{2}$

A Lei de Diretrizes e Bases da Educação Nacional fundamentou a criação do Programa Nacional de Reorientação da Formação Profissional em Saúde Pró-Saúde (lançado em 03/11/2005), através da parceria entre o Ministério da Saúde, Secretaria de Educação Superior e o Instituto Nacional de Estudos e Pesquisas Educacionais Anísio Teixeira (INEP) do Ministério da Educação. Tal programa propicia a formação profissional mais ajustada às perspectivas da atenção básica, visando à saúde. ${ }^{11}$

A formação do cirurgião- dentista ainda é fundamentada em um modelo de ensino que valoriza mais as ciências básicas do que os aspectos de promoção e prevenção, configurando um caminho de mudanças, bem como o desafio que precisa ser assumido e enfrentado pelas Instituições de Ensino Superior. ${ }^{17}$ 
Diante deste contexto, o objetivo deste trabalho foi discutir sobre a abordagem na formação do cirurgião dentista clínico geral para atuar no serviço público e privado.

\section{REVISÃO DE LITERATURA}

Em países extremamente capitalistas, os profissionais monopolizam o saber e somente prestam seus serviços para quem possa remunerá-los. No Brasil, a maioria das universidades são alheias às reais necessidades da população e reproduzem em salas de aula, laboratórios e ambulatórios, realidades distantes das quais o país se encontra. ${ }^{8}$

Na maioria das instituições de ensino em odontologia a tendência de formação do cirurgião- dentista é predominantemente elitista, tecnicista e descontextualizada do contexto sócio econômico, ${ }^{12}$ tendo pouca preocupação com o social e a promoção da saúde, sendo voltada para a prática liberal, ressaltando a necessidade de aperfeiçoamento e especialização em áreas exclusivamente técnicas. ${ }^{17}$

O grande número de profissionais não causa impacto na melhora da saúde bucal no Brasil, pois sua formação acadêmica não está estruturada de forma a coletivizar o atendimento à saúde, sendo a atenção odontológica à população de baixa renda considerada por muitos acadêmicos e profissionais da Odontologia como caridade e filantropismo. ${ }^{12}$

Com relação à prática clínica, as dificuldades são as ações odontológicas dirigidas predominantemente à doença e dependentes tecnologicamente. Identifica-se, no entanto, que as principais deficiências da formação na graduação referem-se ao distanciamento entre o ensino e a realidade socioeconômica e cultural da população. ${ }^{17}$

Assim, além de competência nos domínios de aspectos biológicos envolvidos na prática profissional, deve-se preparar o cirurgião-dentista para que ele também desenvolva competência quanto às dimensões ética e social do seu trabalho. ${ }^{13}$

Os cursos de Odontologia precisam reavaliar o tipo de profissional que estão formando e para que finalidade, levando a reflexão sobre a importância da integração ensino-serviço, para que o acadêmico dentro do seu contexto social, possa compreender o seu papel enquanto profissional de saúde. ${ }^{1}$

Os atuais Projetos Políticos Pedagógicos procuram se adequar a realidade do Sistema Único de Saúde (SUS). As Instituições de Ensino Superior formadoras de recursos humanos, no caso em Odontologia, não devem restringir seu papel social ao atendimento das demandas por serviços de saúde no seu interior, e sim, estendê-lo para fora dele. ${ }^{17}$

A área da Saúde Coletiva tem um papel de grande importância na formação do futuro cirurgião-dentista com o perfil exigido pelas Diretrizes Curriculares Nacionais do curso de Odontologia(implementadas em 2002) e pela sociedade, ou seja, com formação generalista, socialmente sensível e principalmente sempre disposto a aprender. ${ }^{19}$

O sentido social torna-se extremamente relevante no atual contexto da globalização, no qual as relações econômicas, sociais e políticas interagem e se entrecruzam. ${ }^{19}$

A pequena demanda de pacientes, o grande número de profissionais e as mudanças no mundo do trabalho do cirurgião-dentista geram a denominada crise do mercado profissional da prática liberal da Odontologia, na qual o cirurgião-dentista com formação estritamente técnica terá muitas dificuldades de sobreviver. ${ }^{12}$

\section{DISCUSSÃO}

De maneira geral, a odontologia vem sendo repensada, levando à mudança no paradigma da prática da profissão em vários países. A forma tradicional de tratamento, centrada na doença, está gradualmente cedendo espaço para a atenção profissional, cuja ideologia é a prevenção das enfermidades e a promoção de saúde,,$^{17}$ concordando com Reis et al. (2009), ${ }^{18}$ onde relatam que é preciso que estejamos atentos à realidade, buscando perceber as carências da população sob nosso cuidado, procurando conhecer as características demográficas, epidemiológicas, culturais, socioeconômicas e políticas da comunidade, uma vez que só se cuida adequadamente daquilo que se conhece.

No entanto, alguns cursos de graduação em odontologia não aderiram as reformulações das diretrizes curriculares em seus projetos pedagógicos, prevalecendo o modelo de odontologia elitista voltado para o atendimento com ação "curativa", estando de acordo com Garbin et al. (2006), ${ }^{8}$ onde enfatizam que já está mais que na hora dos projetos pedagógicos e as reformulações das diretrizes curriculares saírem da teoria e do papel para mudarem a realidade do ensino e conseqüentemente do País.

Ainda são formados profissionais alheios aos contextos que os cercam, sem terem a oportunidade de vivenciarem experiências na rede pública, sendo estes preparados para atuarem na clínica privada. Esta realidade precisa ser mudada, nossa população neces- 
sita de profissionais capacitados de acordo com a lei de Diretrizes Curriculares Nacionais dos Cursos de Graduação de Odontologia, estando de acordo com Gushi (2004), ${ }^{9}$ quando relatam que a filosofia da Promoção de Saúde vem favorecendo a relação profissional-paciente pelo aprimoramento da terapêutica e pela preocupação com a saúde bucal, levando a necessidade de adequação dos profissionais da área ao mercado de trabalho.

Desta forma as aulas não podem se tornar um lócus de disseminação de resultados obtidos, informações e verdades a serem repassadas, socializadas e consumidas, já que a dimensão do trabalho intelectual perde-se e torna-se difícil alcançar o perfil do egresso proposto pelas Diretrizes Curriculares do curso de graduação: profissional crítico, reflexivo e transformador, conforme Lemos et al.(2005). ${ }^{12}$

Prepara-se o futuro cirurgião-dentista para ser um profissional com boa competência técnica e para atender o mercado privado caracterizado por pequena demanda de pacientes e super oferta de profissionais, ${ }^{12}$ concordando com Figueiredo et al. (2003), ${ }^{5}$ onde citam que o modelo de odontologia elitista com competência técnica para o mercado privado, não contribui para a resolução dos problemas de saúde, acaba por agravar as diferenças sociais e estimular o crescimento do setor privado em detrimento do setor público, favorecendo, assim, a venda e o consumo de um bem que vem sendo considerado uma mercadoria: a saúde.

O exercício da odontologia vem caminhando cada vez mais para sua subdivisão em especialidades. Ainda na graduação, o futuro profissional deve adquirir conhecimentos para se tornar apto a cuidar de pessoas, tanto no serviço privado quanto no serviço público, sendo capaz de atuar na atenção primária dentro do contexto em que os pacientes então inseridos, tendo como base o modelo assistencial alternativo, onde o processo de trabalho do profissional destina o clínico geral para ser atuante na atenção básica e os especialistas nos demais níveis de atenção, de acordo com Chevitarese (2010). ${ }^{4}$

O cirurgião dentista deve ser formado para saber cuidar, não só teoricamente, mas também na prática, uma vez que o sucesso do tratamento a ser realizado muitas das vezes depende da criação de vínculo, escuta ativa e da boa comunicação do profissional com o paciente, em acordo com Santos et al. (2010), ${ }^{20}$ quando relatam que ouvir e integrar diversos aspectos que são trazidos, como as experiências, crenças e hábitos de cada pessoa, ao cuidado e afeto nas rela- ções profissionais diminui a resistência inerente ao ser humano, conduzindo através deste processo interativo, a apropriação do que é importante para manutenção da saúde.

Para que haja uma mudança considerável nos cursos de graduação almejando uma formação de clínico geral realmente, é imprescindível disponibilizar a base teórica e experiência para que o aluno possa atuar de forma a solucionar os casos mais prevalentes de um território, já que este faz parte do contexto de vida do cidadão, tal seja: a escola, trabalho, associações de moradores, unidades básicas de saúde, sua casa, dentre outros.

$\mathrm{O}$ graduando não pode ficar sujeito a ter necessidade de recorrer a cursos de especialização e/ou atualização para adquirir conhecimentos básicos, os quais deveriam ser ofertados nos cursos de graduação, descordando de Pinheiro et al. (2009) ${ }^{17}$ que relatam que a formação do cirurgião dentista é voltada para a prática liberal, ressaltando a necessidade de aperfeiçoamento e especialização em áreas exclusivamente técnicas.

A Lei de Diretrizes e Bases da Educação Nacional fundamentou a criação do Pró-Saúde, propiciando a formação profissional mais ajustada às perspectivas da atenção básica, visando à saúde, ${ }^{11}$ concordando com Morita et al. (2003),,$^{14}$ quando relatam que Diretrizes indicam a necessidade de transformar o modelo de atenção, fortalecendo a promoção e prevenção, oferecendo atenção integral e fortalecendo a autonomia dos sujeitos na produção da saúde.

Algumas instituições têm adotado o modelo do Pró-Saúde em seus cursos de Odontologia, a UNIGRANRIO é um exemplo. Esta universidade disponibiliza as disciplinas de estágio supervisionado I, II e III, sendo assim, no Estágio I os acadêmicos têm a oportunidade de ouvir o que as pessoas têm a dizer e conhecer a realidade da comunidade, realizando levantamento epidemiológico através da ficha $\mathrm{A}$, SIAB (Sistema de Informação da Atenção Básica) e outra específica sobre exames bucais e extrabucais; em seguida, no Estágio Supervisionado II, por meio de dados obtidos no trabalho anterior, propõem estratégias de enfrentamento junto à comunidade, para solucionar e/ou amenizar os problemas encontrados e concluem as ações no Estágio III, em que criam o planejamento das ações e as executam.

Na graduação faz-se necessário a ida a campo para que os alunos possam vivenciar a realidade, concordando com Pelissari et al. (2005), ${ }^{16}$ quando relatam que a formação do cirurgião-dentista deveria contem- 
plar experiências de aprendizado em ambiente extramural e levar em consideração o contexto socioeconômico e cultural da população para a capacitação dos futuros profissionais ao trabalho em serviço público, formando cidadãos trabalhadores para a sociedade, e não somente para o serviço privado.

Tal atividade extramural, oferta aos acadêmicos experiências para que os mesmos se sintam capazes de atuar na atenção básica, estando de acordo com Freixinho et al. $(2010)^{7}$ quando afirmam que os trabalhos executados em ambiente extramural fazem parte de uma metodologia de ensino, a qual capacita os profissionais a terem sensibilidade para trabalhar de acordo com as perspectivas da atenção básica.

Considerando ainda o atual mercado de trabalho para os cirurgiões - dentistas, onde o mesmo encontra-se supersaturado no serviço privado, destaca-se a importância da vivência no serviço público pelos acadêmicos, afim de que tenham experiências para atuarem neste depois de graduados.

Desta forma, hoje no século XXI, o SUS é o melhor empregador, até mesmo quando se trata do primeiro emprego. Segundo o dados divulgados pelo Conselho Federal de Odontologia(CFO).$^{15}$

Segundo Lemos et al. (2005), ${ }^{12}$ as aulas das universidades se tornam lócus de disseminação de resultados obtidos, informações e verdades a serem repassadas, socializadas e consumidas, evidência a qual nos faz refletir: Será que o mestrado que ainda temos é o que precisamos? Será que as pesquisas estão sendo pensadas a fim de que os resultados a curto, médio e longo prazo possam ser incorporados aos conteúdos teóricos e práticos trabalhados em sala de aula, de modo a contribuir para a formação de profissionais cidadãos que sejam sujeitos ativos, capazes de instruir mudanças em suas práticas cotidianas?

Para que tenhamos profissionais recém graduados capazes de atender o paciente de forma eficiente, se faz necessário a participação de professores empenhados, que saibam atuar em diversos contextos sociais, econômicos e culturais, no serviço privado e público, e que tenham clareza para ensinar, concordando com Lazzarin et al. (2007), ${ }^{10}$ que revelam que a formação de cirurgiões-dentistas possivelmente não ocorre com forte embasamento em clínica geral, humanista, crítico e reflexivo, indicando que os cursos de odontologia não se libertaram de práticas ditadas pelo mercado profissional liberal.

É importante ressaltar que para que haja mudança no perfil da formação dos graduandos conforme a lei de Diretrizes Curriculares Nacionais dos Cursos de Graduação de Odontologia, é necessário que haja mudanças também nos profissionais que os formam: professores universitários, concordando com Franco et al. (2009), ${ }^{6}$ quando dizem que esse novo professor necessita aprender a atuar como facilitador e mediador do processo de ensino-aprendizagem, ultrapassando o papel tradicional de mero repassador de conteúdos, carecendo entender o seu tempo e a sociedade na qual se insere, apreendendo valores, linguagens e um novo instrumental tecnológico compatível com os estudantes que freqüentam as Instituições de Ensino Superior.

Os cursos de mestrado precisam resgatar o contato fundamental entre graduandos e mestrandos, para que estes possam aprender a sentir as necessidades de aprendizado dos acadêmicos individualmente, atuando de forma efetiva na transmissão do conhecimento, mudando uma realidade que tornou-se comum: a valorização da pesquisa científica em detrimento à prática de como ser um professor universitário, já que se têm formado mestres para serem pesquisadores e não professores.

\section{CONCLUSÃO}

A abordagem na formação do graduando em odontologia, deve ser ampla, envolvendo tanto a prática na clínica odontológica privada, quanto as idas à campo para vivenciar a realidade dos contextos sociais, econômicos e culturais, com o intuito de tornar este futuro profissional apto para atuar no serviço privado e público.

\section{ABSTRACT}

Approach to training the generalist dentist to act in public and private service. Revolution in the teaching practice

In most dentistry educational institutions, the trend in educating dentists is still predominantly elitist and technique-oriented, and gives more value to the basic sciences than to aspects of health promotion and prevention. It focuses on liberal practice; however, the current political-teaching projects seek to adjust to the reality of the Unified Health System (SUS), providing a professional education more suitable to primary health care. The purpose of this study was to discuss the approach to educating the generalist dentist to act in public and private service. The approach to educating dental students should be broad, qualifying the future professional to act in both public and private service. 


\section{DESCRIPTORS}

Dental students. Education, dental. Education, higher.

\section{REFERÊNCIAS}

1. Almeida AB, Alves MS, Leite ICG. Reflexões sobre os desafios da odontologia no Sistema Único de Saúde. Rev. APS. 2010; 13(1): 126-132.

2. Brasil. Diretrizes Curriculares Nacionais dos Cursos de Graduação em Farmácia e Odontologia. Parecer CNE/CES n ${ }^{\circ}$ 1.300/01, aprovado em 6 de novembro de 2001. [citado 2002 Jan 03]. Disponível em: < http://portal.mec.gov.br/cne/ arquivos/pdf/CES1300.pdf > . Acesso em: 14 setembro 2010.

3. Brasil. Proposta do novo Currículo Mínimo para o Curso de Graduação em Odontologia. Parecer n ${ }^{\circ} 370 / 82$, aprovado em 9 de julho de 1982. Brasília: Documenta 1982;260:46-54.

4. Chevitarese L. Texto de Apoio desenvolvido para as Disciplinas de Estágio Supervisionado do Curso de Odontologia da UNIGRANRIO relacionado com a atenção à saúde. Revista Rede de Cuiidados em Saúde. 2010; 4(2): 1-9.

5. Figueiredo GO, Brito DT, Botazzo C. Ideologia, fetiche e utopia na saúde: Uma análise a partir da saúde bucal. Revista Ciência e Saúde Coletiva. 2003; 8(3):753- 763.

6. Franco LLMM, Soares EF, Martorell LB. O professor do curso de odontologia: Sua formação e os desafios frente ás exigências atuais. Revista Profissão Docente. 2009; 9(20).

7. Freixinho ABS, Aroucha BN, Chevitarese L, Nardino MFV. A importância do autocuidado na saúde bucal. Reviista Rede de Cuiidados em Saúde. 2010; 4(1): 1-5.

8. Garbin CAS, Saliba NA, Moimaz SAS, Santos KT. O papel das universidades na formação de profissionais na área de saúde. Revista da ABENO. 2006; 6(1): 6-10.

9. Gushi LL, Wada RS, Sousa MLR. Perfil profissional dos CDs formados pela FOP no período de 1960-1997. Rev Assoc Paul Cir Dent. 2004; 58(1):19-23.

10. Lazzarin HC, Nakama L, Júnior LC. O Papel do Professor na Percepção dos Alunos de Odontologia. Saúde e Sociedade.
2007; 16(1): 90-101.

11. Lei de Diretrizes e Bases da Educação Nacional. Disponível em: < http://portal.mec.gov.br/arquivos/pdf/ldb.pdf > . Acesso em: 14 setembro 2010.

12. Lemos CLS. A implantação das Diretrizes Curriculares dos Cursos de Graduação em Odontologia no Brasil: algumas reflexões. Revista da ABENO. 2005; 5 (1): 80-5.

13. Lima ENA, Souza ECF. Percepção sobre ética e humanização na formação odontológica. RGO. 2010; 58(2): 231-238.

14. Morita MC, Kriger L. Mudanças nos cursos de Odontologia e a interação com o SUS. Revista da ABENO. 2003; 4(1): 17-21.

15. Notícias CFO. Disponível em: < http://cfo.org.br/todas-asnoticias/noticias/numero-de-cds-no-sus-cresce-49/ > . Acesso em: 1 outubro 2010

16. Pelissari LD, Basting RT, Flório FM. Vivência da realidade: o rumo da saúde para a Odontologia. Revista da ABENO. 2005; $5(1): 32-9$.

17. Pinheiro FMC, Nóbrega- Therrien SM, Almeida MEL, Almeida MI. A formação do cirurgião-dentista no Brasil: contribuições de estudos para a prática da profissão. RGO. 2009; 57(1): 99106.

18. Reis SMAS, Oliveira AG, Gonçalves LC, Costa MM, Olivera JEC, Costa CRR, Reis TS. Formação odontológica: persiste o descompasso entre o perfil do cirurgião-dentista atualmente formado e as demandas da sociedade por saúde bucal. Rev. Ed. Popular. 2009; 8: 86-97.

19. Rodrigues RPCB, Saliba NA, Moimaz SAS. Saúde Coletiva nas estruturas curriculares dos cursos de Odontologia do Brasil. Revista da ABENO. 2006; 6(1): 81-7.

20. Santos SF, Campinas LLSL, Sartori J AL. A afetividade como ferramenta na adesão às orientações sobre educação em saúde bucal na saúde da família. O mundo da saúde. 2010; 34(1): 109-119. 